\title{
Determinants of Sustainable Energy Consumption in Schools ${ }^{\dagger}$
}

\author{
Daiva Dumciuviene ${ }^{1, *}$, Akvile Cibinskiene ${ }^{1}$, Mark Melenhorst ${ }^{2}$ and Jasminko Novak ${ }^{2,3}$ \\ 1 School of Business and Economics, Kaunas University of Technology, LT-44239 Kaunas, Lithuania; \\ akvile.cibinskiene@ktu.lt \\ 2 European Institute for Participatory Media, D-10117 Berlin, Germany; m.melenhorst@eipcm.org (M.M.); \\ j.novak@eipcm.org or jasminko.novak@hochschule-stralsund.de (J.N.) \\ 3 IACS-Institute of Applied Computer Science, University of Applied Sciences Stralsund, \\ 18435 Stralsund, Germany \\ * Correspondence: daiva.dumciuviene@ktu.lt; Tel.: +370-687-47066 \\ + Presented at the Economy, Sustainable Development and Energy International Conference (ESDEIC), \\ Edinburgh, Scotland, UK, 25-27 June 2018.
}

Published: 29 October 2018

\begin{abstract}
In this paper the energy saving behavior and its impacting determinants in schools are analyzed. There is a large number of research on energy saving behavior in residential buildings. However large fraction of the total energy is consumed in public buildings and schools. The issues of sustainable energy consumption behavior are less studied in these types of buildings. Based on the research on energy consumption in residential buildings the determinants of sustainable energy consumption in schools were classified into three groups: psychological and social; sociodemographic and economic determinants; and contextual determinants. A systematic literature review was conducted for the substantially less investigated schools in terms of efficient energy consumption. According the review of research papers, the most important determinants of energy consumption in schools in terms of their influence on consumption were identified: attitudes; incentives/intentions/motivation; knowledge; awareness.
\end{abstract}

Keywords: sustainable energy consumption; energy saving; energy saving behavior; determinants; schools

\section{Introduction}

The review of scientific literature shows that analysis of determinants of energy consumption is important issue regarding energy saving not only in residential buildings but in other types of buildings including schools. At the same time many scientific papers focus more on improvement of technical solutions in terms of energy efficiency then on behavioral aspects of energy saving. However, some researchers [1-4] emphasize on increasing number of technologies used in schools that cause the increase of energy used. In this case the increased consumption of energy could be reduced changing the behavior of customers. It is important to educate and train students improving their knowledge and skills for efficient use of energy. The research of Craig \& Allen [5] states that students can influence adults and help schools drive energy savings. Energy saving behavior learned at school may later be transmitted to the future work place and residential energy use of former students.

Energy consumers in schools are different comparing with public and residential buildings in terms of the activities and time spent in the building. In general, there are more financial incentives to save energy in residential buildings due to clear cost benefit. Employees and students do not have the same financial interest in the school to save energy as they do at home. They have little 
information about amount and cost of energy consumed. Rooms and devices in schools are usually used by multiple occupants.

The change of the behavior in terms of energy consumption may reduce amount of energy used so it is important to investigate the behavior affecting determinants.

\section{Theoretical Background}

Research into behavioural change models has yielded a range of factors, referred to as determinants that can explain human behaviour. These determinants are not only the subject of research into their interrelationships, but also constitute focal points for the design of interventions. One of the most influential determinant models in that respect is the Theory of Planned Behaviour [6], which has also been applied to energy consumption behavior e.g., [7,8]. The Theory of Planned Behaviour (TPB) models the relationship between attitudes, intention, and the target behaviour (i.e., energy consumption).

Frederiks, Stenner and Hobman [9] have classified various individual (socio-demographic and psychological) and situational (contextual and structural) factors that may influence household energy consumption and conservation. The classification presented was taken as a background developing the structural approach for determinants of sustainable energy consumption in schools. Determinants of sustainable energy consumption in schools were classified into three groups: psychological and social; socio-demographic and economic determinants; and contextual determinants.

Psychological, and social determinants have been intensively studied, in order to explain differences between individuals with respect to energy consumption and energy conservation behaviour. Psychological determinants of energy consumption are related to human psychology. Energy consumption and conservation in schools are associated with a wide range of social variables which influence opportunities and constraints. Social determinants can facilitate versus undermine intrinsic motivation.

The concept "sociodemographic" refers to a group defined by its sociological and demographic characteristics. Sociodemographic determinants are attributed to age, gender, education and literacy, employment status, socio-economic status and income, dwelling characteristics, geographical location, etc. Economic determinants are associated to cost and benefit of energy saving. All these characteristics are important in analyzing energy consumption and saving.

An individual's personality can be described and understood in terms of various contexts in which that individual is embedded. The contextual determinants take both personal factors as well as daily activities in the individuals' environment and can be defined in different contexts: historical, cultural, developmental, and interpersonal. Contextual determinants and interrelations between them affect the individual behaviour in consumption and saving which can be applied for the energy saving behaviour as well. Contextual determinants of energy saving describe different types of norms and restrictions, such as laws, regulations and policies, building characteristics, etc.

\section{Method}

The theoretical approach in presenting groups (socio-demographic, psychological and contextual) of energy saving determinants was applied. The determinants of energy saving were analyzed grouping them into three sections: psychological and social; socio-demographic and economic determinants; and contextual determinants.

A systematic literature review was conducted for the substantially less investigated building types-in schools. The review was guided by the following research questions: what are the determinants of energy consumption behaviour in schools?

\section{Research}

The research questions were operationalized into the following set of search terms: energy consumption ((energy OR electricity) AND ((consumption OR efficiency OR saving OR conservation 
OR reduction) OR "energy use" OR "electricity use") AND behav*); school (school OR classroom OR university OR student* OR teacher*) and determinants (predictor* OR determinant* OR factor ${ }^{*}$ OR attitude* OR value* OR knowledge OR belief* OR habit OR norm*).

Identified as some of the most relevant and accessible outlets for research on determinants of energy consumption, the following sources were consulted: ScienceDirect, EBSCO (EconLit, GreenFile), Emerald, WEB of Science, Scopus.

Out of the 62 search results, 31 were selected for the review (50\% acceptance rate). The reviewed school papers consider different type of schools, and when considering determinants for behaviour of students, the age group of the students in the respective schools play a key role.

In the literature reviewed the following theories and theoretical models were used: Theory of Planned Behaviour, Value-Belief-Norm Theory, Theory of Collective Action, Theory of Normative Conduct, Self-Determination Theory, Coherent Theory of Environmentally Significant Behaviour and Theory of Basic Values.

\subsection{Psychological and Social Determinants}

26 papers analysed psychological and social determinants of energy consumption and 33 different determinants were identified in these papers. Attitudes (eight papers), knowledge (seven papers) and awareness (six papers) were the most often analysed determinants.

Psychological and social determinants were analysed mainly in the higher education institutions (16 papers), five papers studied schools in general and one paper in primary school. In five papers the target group was school's employees, three papers focused on office workers in schools, five papers on students. All persons associated to the higher education institutions were the focus of two papers while other three papers focused on different combinations of target groups: staff and graduate students; staff, graduate students and faculty; students and administrative staff.

\subsection{Socio-Demographic and Economic Determinants}

Socio-demographic and economic energy saving behaviour determinants in schools were analysed in four papers. Authors of these papers focused on seven socio-demographic and economic determinants (demographic factors, district population, household income, learning, social recognition, funding to overcome energy saving barriers, average property value).

Authors of three papers conducted research in higher education schools and only one paper focused on school in general. All persons associated to the building were studied in two papers. Campus employees, students and students/administrative staff were in the focus of one paper each.

\subsection{Contextual Determinants}

Contextual energy saving behaviour determinants in schools were analyzed in nine papers and nine different determinants (institutional policy, activity based, physical environment constraints, sense of community, energy culture, technology upgrades, metering consolidation, control system changes, levels and occupant's intervention) were investigated in these papers. The determinant "Institutional policy" was highlighted in four papers while the rest of determinants were studied in one paper each.

Six papers studying contextual determinants focused on higher education institutions while schools in general and secondary school were analyzed in one paper each. All persons associated to the building and school staff were analyzed in two papers each. One study focused on graduate students, faculty and staff, another study analyzed school staff and students and one more study had students and administrative staff in focus.

\section{Conclusions}

Energy consumers in schools are different comparing with public and residential buildings. Occupants in residential buildings have more financial incentives to save energy. Students in schools 
do constantly change their location and schools are usually more occupied during the first half of the day.

The literature reviewed revealed that the following theories and theoretical models were used to investigate determinants of sustainable energy consumption in schools: Theory of Planned Behaviour, Value-Belief-Norm Theory, Theory of Collective Action, Theory of Normative Conduct, Self-Determination Theory, Coherent Theory of Environmentally Significant Behaviour and Theory of Basic Values.

According the review of research papers, the most important determinants of energy consumption in schools in terms of their influence on consumption are: (1) attitudes, (2) incentives/intentions/motivation, (3) knowledge, (4) awareness.

Author Contributions: All authors equally contributed to all parts of the paper.

Acknowledgments: This work is partially supported by the "enCOMPASS-Collaborative Recommendations and Adaptive Control for Personalized Energy Saving" project funded by the EU H2020 Programme, grant agreement no. 723059.

Conflicts of Interest: The authors declare no conflict of interest.

\section{References}

1. Mtutu, P.; Thondhlana, G. Encouraging pro-environmental behaviour: Energy use and recycling at Rhodes University, South Africa. Habitat Int. 2016, 53, 142-150.

2. Altan, H. Energy efficiency interventions in UK higher education institutions. Energy Policy 2010, 38, 7722 7731.

3. Amutenya, N.; Shackleton, C.M.; Whittington-Jones, K. Paper recycling patterns and potential interventions in the education sector: A case study of paper streams at Rhodes University, South Africa. Resour. Conserv. Recycl. 2009, 53, 237-242.

4. Marcell, K.; Agyeman, J.; Rappaport, A. Cooling the campus: Experiences from a pilot study to reduce electricity use at Tufts University, USA, using social marketing methods. Int. J. Sustain. High. Educ. 2004, 5 , 169-189.

5. Craig, C.A.; Allen, M.W. The impact of curriculum-based learning on environmental literacy and energy consumption with implications for policy. Util. Policy 2015, 35, 41-49.

6. Ajzen, I. The theory of planned behaviour. Organ. Behav. Hum. Decis. Process. 1991, 50, 179-211.

7. Tetlow, R.M.; van Dronkelaar, C.; Beaman, C.P.; Elmualim, A.A.; Couling, K. Identifying behavioural predictors of small power electricity consumption in office buildings. Build. Environ. 2015, 92, 75-85.

8. Gadenne, D.; Sharma, B.; Kerr, D.; Smith, T. The influence of consumers' environmental beliefs and attitudes on energy saving behaviours. Energy Policy 2011, 39, 7684-7694.

9. Frederiks, E.; Stenner, K.; Hobman, E. The Socio-Demographic and Psychological Predictors of Residential Energy Consumption: A Comprehensive Review. Energies 2015, 8, 573-609.

(C) 2018 by the authors. Licensee MDPI, Basel, Switzerland. This article is an open access article distributed under the terms and conditions of the Creative Commons Attribution (CC BY) license (http://creativecommons.org/licenses/by/4.0/). 